\title{
DEVELOPMENT OF IOT BASED SMART SENSING SYSTEM FOR THE DETECTION OF SOIL NUTRIENTS AND ENVIRONMENTAL CONDITION TOWARDS PRECISION AGRICULTURE
}

\author{
J. S. VASANTH ${ }^{1}$, K. BALAJI ${ }^{2}$, C. S. SUMATHI ${ }^{3}$, P. KRISHNAKUMAR ${ }^{4}$ \\ ${ }^{1}$ Alumni of Amrita School of Engineering, Amrita Vishwa Vidyapeetham, Ettimadai, Coimbatore,Tamil Nadu, India \\ ${ }^{2}$ Teaching Assistant (Electronics), Department of Processing \& Food Engineering, AgriculturalEngineering College \& \\ Research Institute, TNAU, India \\ ${ }^{3}$ Assistant Professor (Computer Science), Agricultural Engineering College \& Research Institute,TNAU, Kumulur, India \\ ${ }^{4}$ Teaching Assistant (Agrl. Engg.), Department of Processing \& Food Engineering, AgriculturalEngineering College \& \\ Research Institute, TNAU, Kumulur, India
}

\begin{abstract}
Our country's economic development is highly dependent on farming. In the research, we suggest a way to develop a smart farming system that uses the cutting edge of Internet of Things (IoT) and Cloud computing to assist the farmers to enhance the way of farming. The research primarily lays emphasis on identifying the level of soil nutrients and environmental factors. Nitrogen, Phosphorous as well as Potassium were the major soil nutrients accountable for plant development. Soil moisture, pH level along with the temperature level of the environment is reported. In the suggested structure the soil specimen is taken as input as well as some chemical reactions are carried out. The colour change of the specimen was sensed through the colour sensors and the values are processed by a controller. The values are delivered to the user for low cost farming solutions to adapt with the socio-economic conditions of small scale farming in developing countries. An Android mobile application has been developed to show the obtained result from the controller.

KEYWORDS: Arduino Mega2560, Node MCU ESP8266; Temperature \& pH Sensor; Soil Moisture Sensor; Colour Sensor; MIT APP inventor: Soil nutrients
\end{abstract}

Received: Sep 19, 2020; Accepted: Oct 09, 2020; Published: Nov 10, 2020; Paper Id.: IJCSEITRDEC20204

\section{INTRODUCTION}

The Green Revolution during 1960s-1980s has led to a considerable rise of crop produce, saving many millions of people from famine. One of the primary elements in the Green Revolution is the implication of synthetic fertilizers along with pesticides. Nitrogen, Phosphorous and Potassium are the three major nutrient elements required by plants and supplied through chemical fertilizers. Iron, Manganese, Copper, Zinc, Boron, Molybdenum and Chlorine were the slight soil micronutrients which may be applied to plants when there is a need or under deficient conditions (Brady et al., 2008). The standard of the soil was estimated in regard to three major nutrients, i.e., Nitrogen, Potassium and phosphorus (Ramane et al., 2015). Nitrogen was found to exist in the form of ammonium $(\mathrm{NH} 4+)$ and nitrate (NO3-). Potassium is present in its ionic form i.e. $\mathrm{K}+$. The orthophosphates, H2PO4- and HPO42- were macro mixture of phosphorus which was required for plants development (Jain et al., 2020). These nutrients are needed for enhancing the yield of crops. Specially, N serve as building block accountable for rising production, standard as well as blooming of plants. P and $\mathrm{K}$ helps for root development, flowering, fruiting and yield as 
well as creating resistance to pests and diseases.

Chemical fertilizers are made industrially and contain certain standards of Nitrogen, Phosphorus along with Potassium, and their manipulation leads to ground water pollution through Eutrophication of water bodies as well as also air pollution through various ways of nutrient loss of nutrients (Nitrogen). Nearly $60 \%$ of applied $\mathrm{N}$ and $75 \% \mathrm{P}$ undergoes loss and leads to environmental problems. Due to loss of nutrients by various ways and the loss of soil productivity, expected yields are not obtained by the farmers, which results in high usage of fertilizers.

Since the world population is constantly on the rise, the demands are high in the agriculture field despite challenges like climate change. In order to handle such sophisticated tasks and increase the quality of production, we need more automation. The labour needed for agriculture has been on the decline in several countries. New technologies must be introduced and adopted in the industry which will help lower costs and increase efficiency. To deal with these challenges, we can make use of smart-farming. It is a broad term that is based on IoT and is an emerging area that refers to the management of farms with the use of modern information and communication technologies in order to increase the quantity as well as quality that the farm produces.

Some of its applications include using systems based on different types of sensors to measure different factors which influence production. For example, sensors to detect light, humidity and moisture are often used these days. In farming, soil macro along with micronutrients, organic matter, $\mathrm{pH}$ level, pesticides, pathogens and temperature were the significant variables used to analyse the standard of the soil (Weil et al., 2003). Another application of IOT in agriculture includes the usage of drones and robots to constantly monitor the crops and the field. It helps in enhancing the health assessment of crops, and soil analysis. Farm owners can use IOT applications for livestock tracking and get information regarding the location and health which can help identify diseases among the cattle quickly.

\section{A. Soil Nutrient Analysis}

\section{i) Electro-chemical Sensors}

Conventionally soil nutrients are analysed through sampling of soil followed by processing, prep treatment and finally analysis and estimation through Spectrophotometer or through ICP (Inductively Coupled Plasma-optical emission spectrometry). These methods are highly precise but take a lot of time. Generally the major nutrients are quantified mainly since these are the bigger inputs in agriculture that lead to higher growth and yield of crops. STCR (Soil Test Crop wise Recommendation) for fertilization is widely recommended as it is mainly based on the soil nutrient analysis. Due to consumption of more time as well as to reduce the dependence and cost for estimations, novel methods for soil nutrient detection with reliability are needed for nutrient recommendation in precision farming.

Sensors can measure wide variety of essential properties of soil. An electrochemical sensor comprises of an Ion particular membrane that particularly answers to a targeted Ion, and a transducer that changes the reactions into detectable electrical signals (Lin et al., 2007). Electrochemical sensors can contribute the most significant kind of details required for precision farming like soil nutrient levels and environmental factors like $\mathrm{pH}$, soil moisture and temperature $\mathrm{pH}$. There are two types of electrochemical sensors used for detection of soil nutrients such as Ion Selective Electrode (ISE) and Ion Selective Field Effect Transistor (ISFET) (Lin et al., 2007). ISE's were noted to detect soil Nitrate (Dahnke, 1971; Hansen, 1977), Ammonium (Banwart, 1972; Simeonov, 1976) and Potassium (Mei, 1982; Wang, 1992). Many reports suggested the PVC-based membrane ISE's for the detection of Phosphate contents in biological samples (Fibbioli, 2000; Wroblewski, 
2001). The electrochemical sensing collaborated with Ion particular membrane based transducers was an attractive application to observer soil variables like Nitrate, Phosphate, Potassium along with other soil variables (Lin et al., 2007; Ali et al., 2019 a).

(Ali et al., 2019 a) progressed a reusable electrochemical soil nitrate sensor utilizing a Nanocomposites printed circuit board. This Ion-selective membrane-based sensor was efficient of detecting nitrate-nitrogen as well as greatly sensitive at the range of $1 \mathrm{ppm}$ to $1500 \mathrm{ppm}$ in soil slurries. A highly sensitive Ion-selective field effect transistor (ISFET) based soil sensor integrated using polyvinyl chloride (PVC)-based Ion-selective nitrate membrane collaborated with a flow injection system was fabricated for soil analysis (Birrel and Hummell, 2001).

Another ISFET based sensor system has been evolved for detection of soil ions involving $\mathrm{K}+, \mathrm{pH}$ level, $\mathrm{Ca} 2+$, and NO3 - in aqueous solutions (Birrel and Hummell, 2001). The maximum advantages of soil nutrient observation utilizing electrochemical sensors were high sensitivity, fast detection, simplicity of utilize as well as cost-effectiveness.

\section{B. Colour Sensors}

A colour sensor was a "photoelectric sensor" that can emit light from a transmitter, and uses a receiver to notice the light which is indicated back from the object used for detection. Such sensors have the ability to differentiate between primary colours like red, blue and green. They can also detect the intensity of the light reflected from the object. These are also called as colour detectors. This process is determined by the different filters which are used in these sensors. These sensors reject UV light, infrared light and only reflect and absorb light in the Red green blue (RGB) scale with different wavelengths.

These sensors are utilized to estimate also noticed the existence of NPK content of the soil. The colour sensor has a nutrition observation sensor consisting of four LEDs as light origin and a light detector (a photodiode). The soil absorbs the light from the LED and reflects it back. By selecting suitable filter readings in the photodiode it is easy to find out the intensity of all the colours (Jain et al., 2020). The current-to-frequency converter transforms these readings into square waveform using the frequency which was shortly proportional to the light intensity of the selected colour. This will be read using the Node MCU. Lastly, the output from the colour sensor will be transformed to digital readable form which is displayed on the screen. This will be more economically viable and acts as a suggested solution for the next generation cropping structure. Here the Smart Soil Quality Predictor checks the amount of three main nutrients viz., N, P along with K in the soil in comparison the observed one with the standard absorption wavelength. It will help the farmers to determine and calculate the amount of fertilizers needed for the crop themselves. The excess use of fertilizers and wastage of money can be avoided through this method.

\section{LITERATURE SURVEY}

In order to decide the quantity of nutrients to be added to the soil for any particular crop and to increase the crop fertility, the Nitrogen, Phosphorous and Potassium contents of the soil should be measured. The quality of the soil is improved and that results in production of good quality crop whose demands are increasing. (Ramane et al., 2015) developed fibre optic based colour sensors to decide N, P, and K utilities in the soil trial. The calorimetric estimate of aqueous compound of soil was conducted.

To reduce the artificial observing of the area as well as obtain the details through mobile application, this system was developed. In this study the soil was evaluated through several sensors like $\mathrm{pH}$ sensor, temperature sensor, along with 
humidity sensor. The obtained values were supplied to the field manager via the Wi-Fi router as well as the crop recommendation was created using a mobile app. Automatic irrigation system was conducted and crop image is captured (Anandhi et al., 2017).

Raut and Varma (2017) developed the sensors for a mechanized irrigation system also to examine the quantity of nutrients ( $\mathrm{N}, \mathrm{P}$ and $\mathrm{K})$. The nutrient quantities in the soil specimen were decided in comparison to the compound using colour chart. This will explain the quantity of nutrient as high, medium, and low. When there was an alteration in temperature as well as humidity of the environment, these sensors detect it also provide an interrupt signal to ARM 7 processor, hence starting the irrigation. All these operations will be improved to the user through email forwarded using the system PC via IoT.

On the go sensors allow us to rapidly quantify the soil variability which allows precision soil management and it is also non-destructive (Bah et al., 2012). Using electro chemical and electro-magnetic sensors for this process is promising. Since there are many risks associated with climate change and the ever growing population, the productivity in the field must be high. To ensure that such challenges are overcome, the soil productivity must be sustainable and should maintain a high yield of crops. Using sensor technologies for managing nutrients in the soil is a step in the right direction.

A comprehensive module for assessing the soil nutrients as well as the environmental factors was developed by (Smitha et al., 2020). In order for estimating the NPK content of the soil, different sensors for measuring pH, soil moisture, temperature, humidity and colour were used. The results provided by the sensors are sent to the cloud for storage and they are analysed, which helps the end-users select better crops. Base on these results suggestions, growth of the suitable crops are made. Further a Wi-Fi module interfaced with Arduino is enabled, which is used to display the test result data and also a list of particular crops suitable for the tested soil. Further, a web portal is created which gives information about the fertilizer(s) required for their crops.

\section{METHODOLOGY}

Over all methodology proposed for NPK estimations through colour sensors and $\mathrm{pH}$, moisture and temperature sensor for assessing soil properties along with Arduino Mega and Android App have been depicted through the following picture fig 1. 


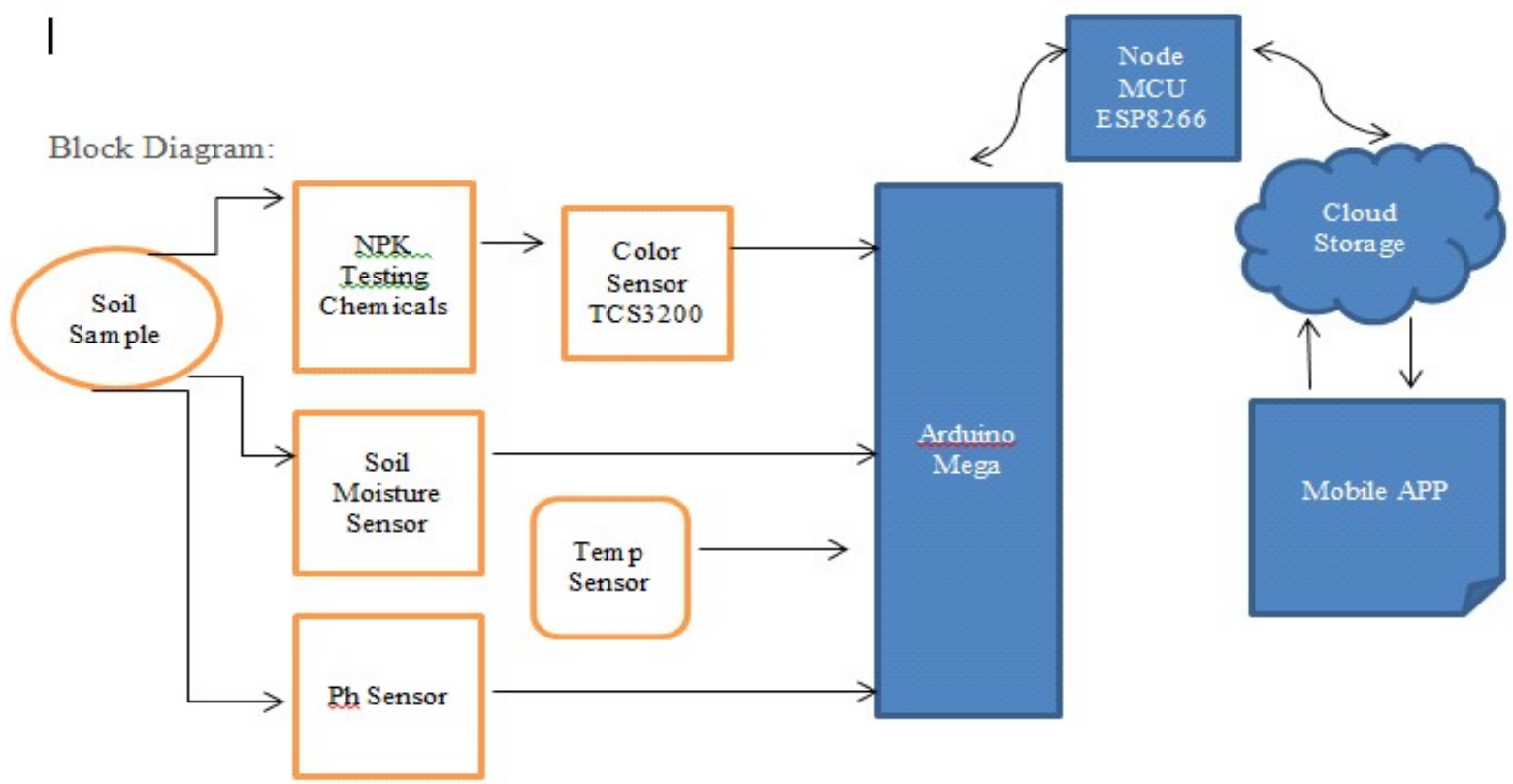

Figure 1: Overall Block Diagram

\section{A. Node MCU ESP8266 Controller}

The Node MCU ESP8266 development board shown in fig 2 comes with the ESP-12E module having ESP8266 chip with 32 bit LX106 RISC microprocessor. It functions at $80 \mathrm{MHZ}$ with 128KB RAM along with 4MB of flash memory to stock program and data. It has high processing power using in-built Wi-Fi/Bluetooth as well as sleep mode create it reliable for IoT Projects. It supports several serial communication protocols like UART, SPI and I2C interface.

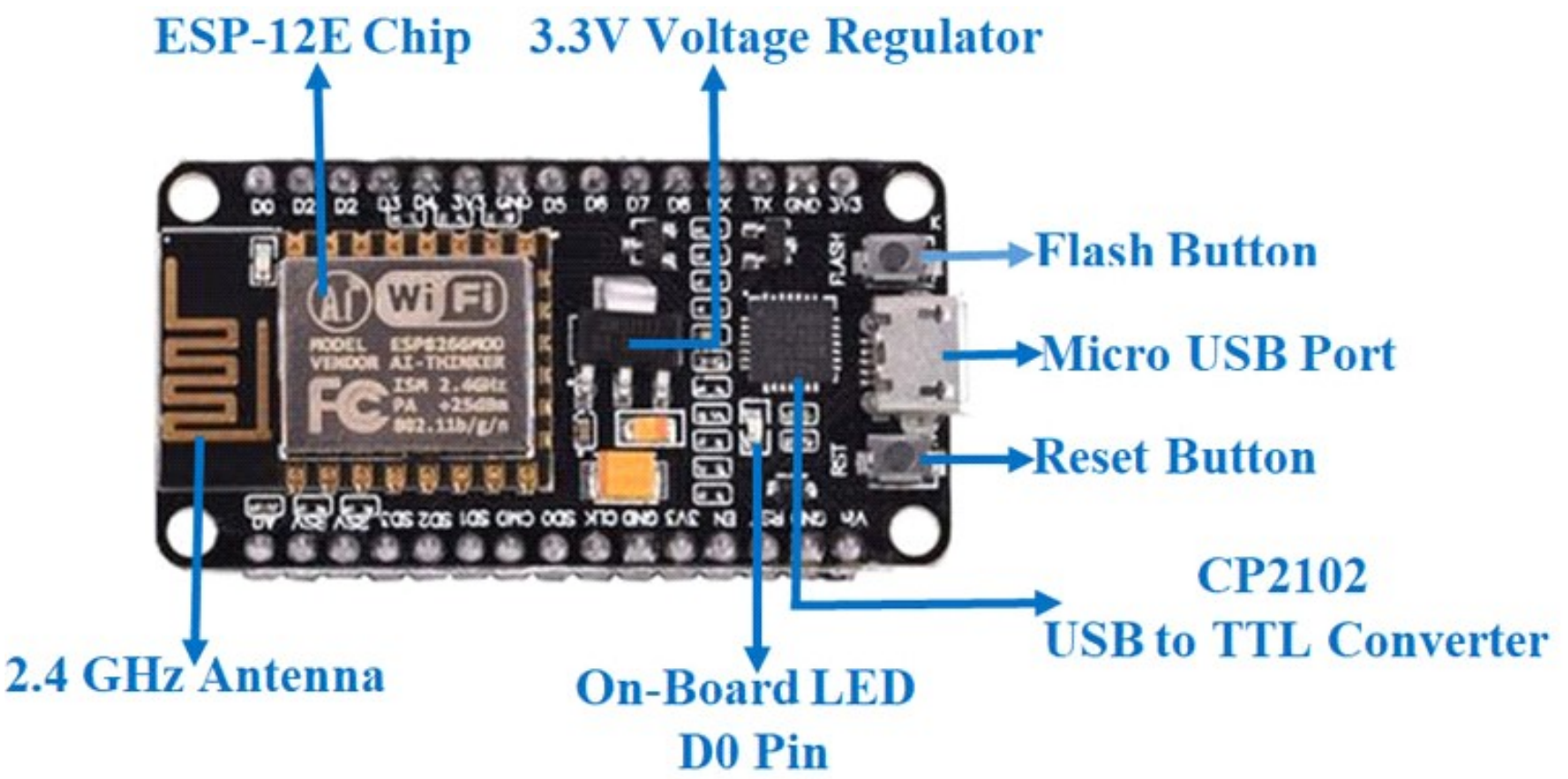

Figure 2: Node MCU ESP8266 development board

\section{B. NPK Testing Chemicals}

Important nutrients of the soil are Nitrogen, Phosphorous and Potassium that can be estimated easily with this colour 
sensor kit. The evaluation was provided using MT 5009-0 NITRATE reagent with the $2.5 \mathrm{ml}$ of soil suspension sample. After 30s, pink colour is evolved showing the presence of Nitrogen in the soil and based on the intensity of the colour, the prediction of nutrient status (low to high) is found out. The test is supplied with MT 5010-0 PHOSPHATE reagent, with the $2.5 \mathrm{ml}$ of soil suspension sample. After $30 \mathrm{~s}$, blue colour is evolved showing the presence of Phosphorous in the soil and based on the intensity of the colour, the prediction of nutrient status (low to high) is found out. Then, the evaluation was provided using MT 5002-0 POTASSIUM reagent with the $2.5 \mathrm{ml}$ of soil suspension sample. After $30 \mathrm{~s}$, red colour is evolved showing the presence of Potassium in the soil and based on the intensity of the colour, the prediction of nutrient status (low to high) is found out.

\section{Colour Sensor (TCS3200):}

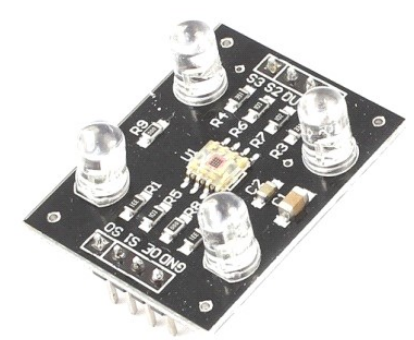

Figure 3: Colour sensor (TCS3200)

TCS3200 chip shown in fig 3 is the main part of the module which is present to do light to frequency conversion. It contains four distinct kinds of filter coated diodes with $8 \times 8$ array of photodiodes, 16 photodiodes has red filters, 16 photodiodes has blue filters, 16 has Green filters along with other 16 photodiodes were transparent with no filters. This filter has activated using S2, S3 selection inputs. This module is used in colour sorter operations, colour comparison, matching tests etc.

\section{Soil Moisture Sensor (FC-28):}

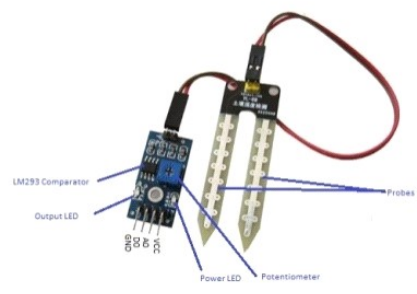

Figure 4: Soil Moisture Sensor (FC-28)

The Soil Moisture fig 4 using operating voltage between 3.3v to $5 \mathrm{v}$ which include the potentiometer that fix the threshold value and its type of interface is analogue. It estimates the volumetric content of water inside the soil as well as provides output the moisture. The soil moisture sensor with two probes allows the electricity to move via the soil as well as get the resistance value to estimate the moisture utility. While the water content was additional, the soil carries out additional current and so the resistance is low.

\section{E. PH Sensor (SEN0249)}


The PH value is very important factor for plant growth as well as soil microbes. Plants differ from each other with suitable PH value. The PH probe (fig 5) has kit attached with a spear like protection shield made of stainless steel with a tip. This tip is directly stabbed into the soil to measure the PH level accurately. Its measuring range is between 0 to $10 \mathrm{PH}$.

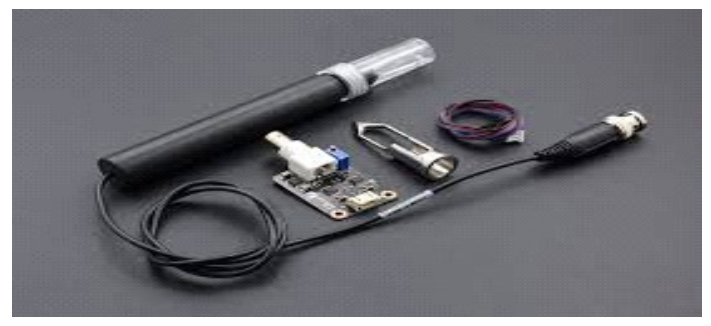

Figure 5: PH Sensor (SEN0249)

\section{F. Temperature Sensor (TMP36):}

The temperature of soil acts an important part in crop growth and soil microbial population. The TMP36 temperature shown in below fig 6 measure temperature in the range $\left(\left(-50^{\circ} \mathrm{C}\right.\right.$ to $\left.125^{\circ} \mathrm{C}\right)$. This sensor uses the property of diode instead of temperature sensitive resistor. The sensor measures the voltage between 0 and 1.75VDC based on it.

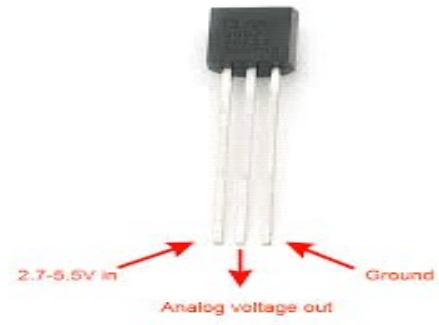

Figure 6: Temperature Sensor (TMP36)

\section{G. Schematic Diagram:}

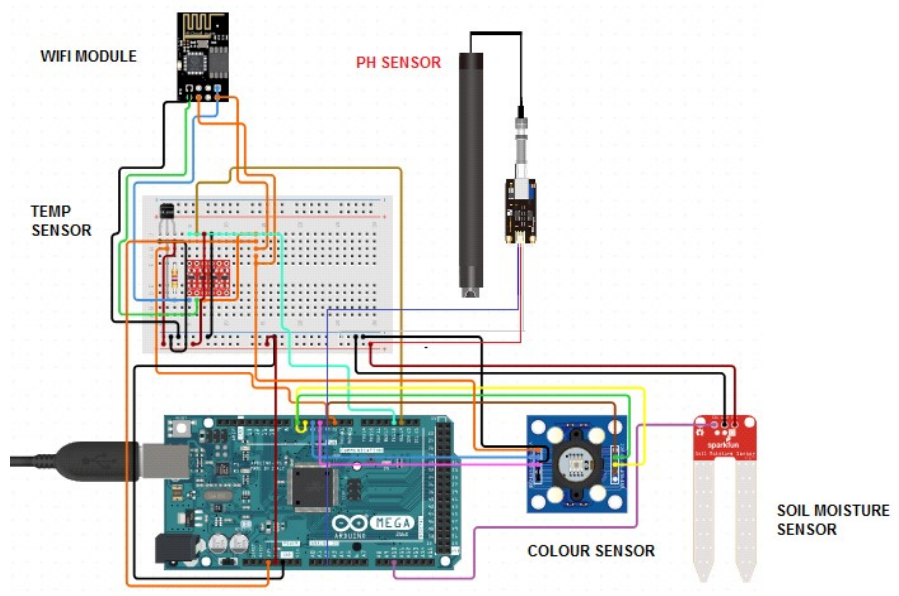

Figure 7: Schematic Diagram using Circuito IO App Software

The TCS3200 sensor was associated with the digital pins as well as VCC of Arduino Mega 2560. The temperature sensor and PH sensors has been associated to VCC, GND and digital pins of Arduino Mega board whereas the soil moisture sensor is associated with the VCC, GND and analogue pins of Arduino Mega board. The Node MCU ESP8266 
Controller is interfaced with arduino Mega to provide reliable Wi-Fi connectivity. The above schematic diagram fig 7 is designed using the Circuito IO app maker software.

\section{H. Cloud Storage}

Cloud Firestore is the latest database for mobile app development. It is real time database with large data storing capacity and provides an efficient, low latency for mobile app and synchronizes the clients in user friendly manner.

\section{G. Android Application}

The purpose of this app was to support the farmers obtain the soil description at real-time. All the necessary information was fetched from the cloud storage (firebase) through employing this android app. It is secure and user friendly. MIT App Inventor was a web application integrated development environment which is used to create the app in this work. The App named as VBSK app (Vasanth, Balaji, Sumathi, Krishnakumar).

\section{WORKING}

The prediction of Soil Nutrient (NPK Level) status based on the colour after chemical reagent is sensed and found by the colour sensor, the environmental status is found by the temperature, soil moisture and $\mathrm{pH}$ sensor and other sensors are interfaced with controller. The controller sends the information to the Firebase through node MCU Wi-Fi module. In the real time firebase database, all the data is stored securely and those values are transmitted to Android mobile App VBSK.

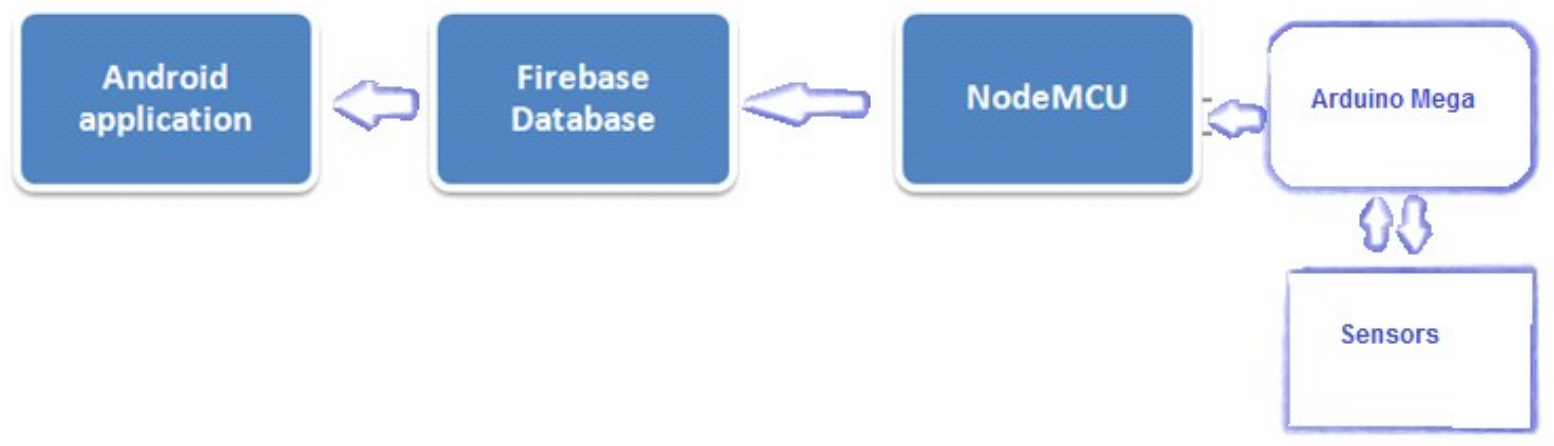

Figure 8: Working Module

\section{EXPERIMENTAL RESULTS}

The paper outcome acquired from the proposed system has indicated that the system functioning was precise as well as definitive. In this system, colour sensors detect the colour of the sample after the reaction in comparison with the standard range of wavelengths absorbed through particular nutrient. Different colours are developed for different wavelengths and it provides out the majority precise colours' wavelength that was nearly equivalent to the light absorbed by the specific nutrient. Then that specific photodiode filter was switched on for the nutrient estimation. The experiment was indicated the soil nutrient level recognition was very useful for the farmers to limit the over use of fertilizers in the farm area so as to increase the productivity and to maintain the soil health. The $\mathrm{pH}$ sensor will depict the degree of acidity / alkalinity of the soil, which will also help the farmers to pick suitable crops and manage the nutrients. Temperature and moisture sensors will be helpful to the farmers for scheduling the irrigation. The sensor values are sent to the Android app VBSK app shown in below fig 9 through firebase. 


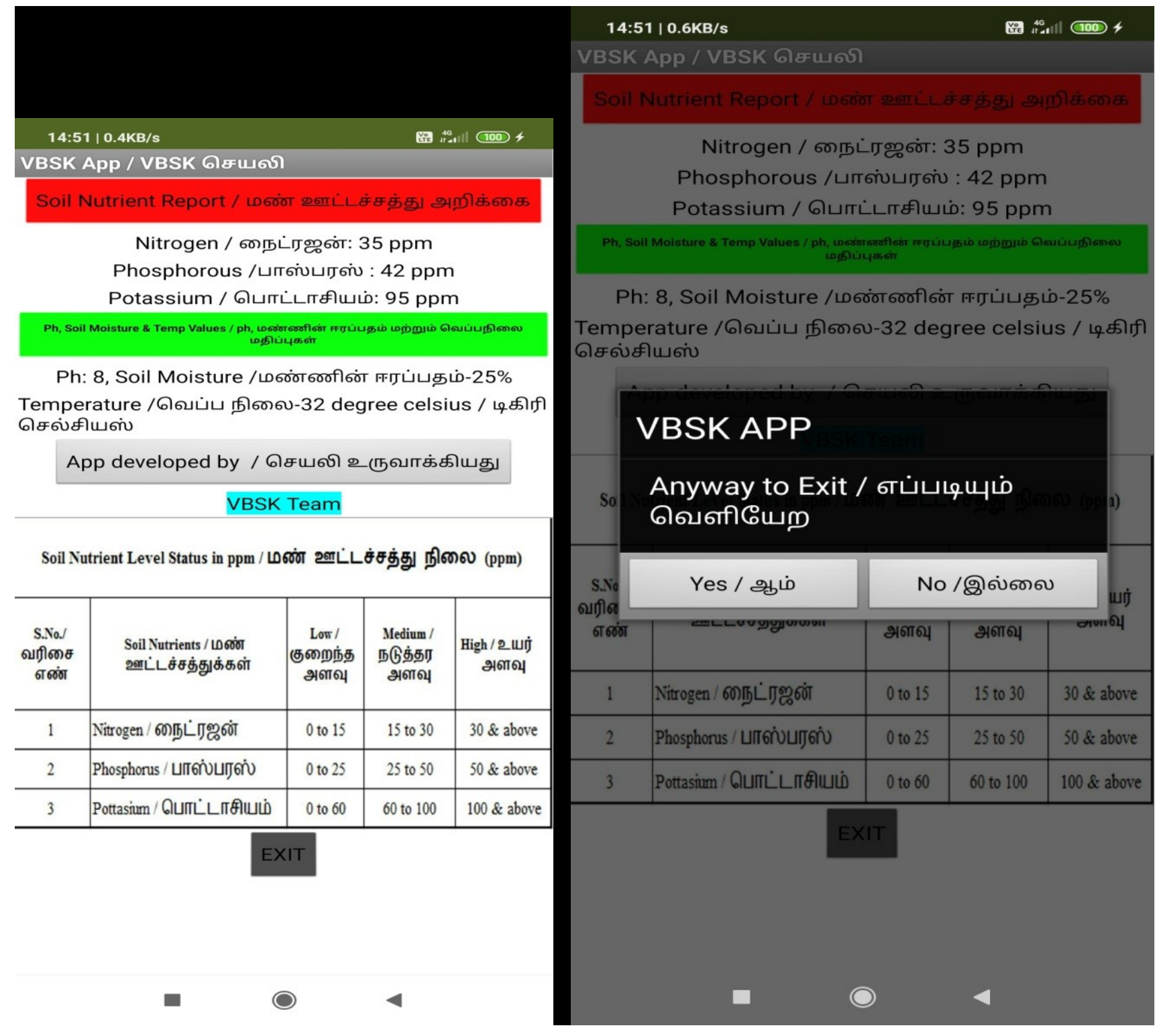

Figure 9: Screen Shot of Android App (VBSK App)

\section{CONCLUSIONS}

This system analyses the soil specimen as the input and performs the chemical reactions utilizing specified reagents. The colour from the soil samples are sensed by the colour sensor. The soil moisture sensor as well as temperature sensor was also employed to examine the moisture level along with temperature. Arduino Mega 2560 interfaced using Wi-Fi microchip ESP8266 was utilized to obtain the information from the sensors as well as to send that information to the cloud. An android application was constructed to indicate the evaluation outline along with suggestions. Colour sensors were utilized in the system in spite of electrochemical sensors to create it cost-effective for the end users. Further study about the standard data on each parameter may be interlinked, and so that the app would show the recommendations for each of the value obtained through the sensor. This enables the farmers to go digital and not depend on scientific manpower.

\section{REFERENCES}

1. Brady, N. C., Weil, R. R., \& Weil, R. R. (2008). The nature and properties of soils (Vol. 13, pp. 662-710). Upper Saddle River, 
NJ: Prentice Hall.)

2. Ramane, D. V., Patil, S. S., \& Shaligram, A. D. (2015, February). Detection of NPK nutrients of soil using Fiber Optic Sensor. In International Journal of Research in Advent Technology Special Issue National Conference ACGT 2015 (pp. 13-14).

3. Jain, A., Saify, A., \& Kate, V. (2020). Prediction of Nutrients (N, P, K) in soil using Colour Sensor (TCS3200). International Journal of Innovative Technology and Exploring Engineering, ISSN: 2278-3075, 9(3), 1768-1771

4. Weil, R. R., Islam, K. R., Stine, M. A., Gruver, J. B., \& Samson-Liebig, S. E. (2003). Estimating active carbon for soil quality assessment: A simplified method for laboratory and field use. American Journal of Alternative Agriculture, 3-17.

5. Lin, J., Wang, M., Zhang, M., Zhang, Y., \& Chen, L. (2007, August). Electrochemical sensors for soil nutrient detection: Opportunity and challenge. In International Conference on Computer and Computing Technologies in Agriculture (pp. 13491353). Springer, Boston, MA.

6. KUMAR, S. RAMESH, et al. "Design and fabrication of autonomous robot for precision agriculture." (2018). International Journal of Mechanical and Production Engineering Research and Development (IJMPERD) 8.3, Jun 2018, 385-392

7. Dahnke, W. C. (1971). Use of the nitrate specific ion electrode in soil testing. Communications in Soil Science and Plant Analysis, 2(2), 73-84.

8. Hansen, E. H., Ghose, A. K., \& Růžička, J. (1977). Flow injection analysis of environmental samples for nitrate using an ionselective electrode. Analyst, 102(1219), 705-713.

9. DODDAMANI, ABDULGAFFAR, and SHIDDANAGOUDA YADACHI. "ROLE OF PRECISION AND AUTOMATION TECHNIQUES IN DOUBLING THE FARMER'S INCOME." International Journal of Agricultural Science and Research (IJASR) 8.3 Jun 2018, 99-112

10. Banwart, W. L., Tabatabai, M. A., \& Bremner, J. M. (1972). Determination of ammonium in soil extracts and water samples by an ammonia electrode. Communications in soil science and plant analysis, 3(6), 449-458

11. Simeonov, V., Asenov, I., \& Diadov, V. (1976). Successive Determination of pH and Ammonical Nitrogen in Soil Samples. Analytical Letters, 9(11), 1025-1029.

12. TianHua, W. Q. (1992). Simultaneous Determination of Sodium and Potassium in Soil Extract by Ion Selective Electrode [J]. Journal of Northwest Sci-Tech University of Agriculture and Forestry, 3.

13. Sushanth, Kallem, RAJ KUMAR, and ANIL BHARDWAJ. "Soil mapping of Patiala-Ki-Rao watershed in Shivalik Foot-Hills using GIS." International J. of Agri. Sci. Res.(IJASR) 9.2 (2019): 1-8.

14. Fibbioli, M., Berger, M., Schmidtchen, F. P., \& Pretsch, E. (2000). Polymeric membrane electrodes for monohydrogen phosphate and sulfate. Analytical chemistry, 72(1), 156-160.

15. Wróblewski, W., Wojciechowski, K., Dybko, A., Brzózka, Z., Egberink, R. J., Snellink-Ruël, B. H., \& Reinhoudt, D. N. (2001). Durable phosphate-selective electrodes based on uranyl salophenes. Analytica chimica acta, 432(1), 79-88.

16. Ali, M. A., Wang, X., Chen, Y., Jiao, Y., Castellano, M. J., Schnable, J. C., ... \& Dong, L. (2019, June). Novel All-Solid-State Soil Nutrient Sensor Using Nanocomposite of Poly (3-Octyl-Thiophene) and Molybdenum Sulfate. In 2019 20th International Conference on Solid-State Sensors, Actuators and Microsystems \& Eurosensors XXXIII (TRANSDUCERS \& EUROSENSORS XXXIII) (pp. 170-173). IEEE.

17. Bagalkote, Ismail S., and ANUP S. VIBHUTE. "Multiresolution Analysis and Implementation of Grape Species Classification Using Neural Network." International Journal of Agricultural Science and Research 6.1 (2016): 37-46. 
18. Birrell, S. J., \& Hummel, J. W. (2001). Real-time multi ISFET/FIA soil analysis system with automatic sample extraction. Computers and Electronics in Agriculture, 32(1), 45-67.

19. Birrell, S. J., \& Hummel, J. W. (2000). Membrane selection and ISFET configuration evaluation for soil nitrate sensing. Transactions of the ASAE, 43(2), 197.

20. Ramane, D. V., Patil, S. S., \& Shaligram, A. D. (2015, February). Detection of NPK nutrients of soil using Fiber Optic Sensor. In International Journal of Research in Advent Technology Special Issue National Conference ACGT 2015 (pp. 13-14).

21. Ananthi, N., Divya, J., Divya, M., \& Janani, V. (2017, April). IoT based smart soil monitoring system for agricultural production. In 2017 IEEE Technological Innovations in ICT for Agriculture and Rural Development (TIAR) (pp. 209-214). IEEE.

22. Raut, R., Varma, H., Mulla, C., \& Pawar, V. R. (2018). Soil monitoring, fertigation, and irrigation system using IoT for agricultural application. In Intelligent communication and computational technologies (pp. 67-73). Springer, Singapore.

23. Bah, A., Balasundram, S. K., \& Husni, M. H. A. (2012). Sensor technologies for precision soil nutrient management and monitoring. American Journal of Agricultural and Biological Sciences, 7(1), 43-49.

24. XX Smitha, K., Samantha, K., Sharanya, B., Shivani, S., and Yashada, G. (2020). IOT Enable Soil Testing \& NPK Nutrient Detection. JAC : a journal of composition theory. 13 (5), 310-318 

